http://jmscr.igmpublication.org/home/ ISSN (e)-2347-176x ISSN (p) 2455-0450

crossref DOI: https://dx.doi.org/10.18535/jmscr/v7i10.45

Journal Of Medical Science And Clinical Research

IGM Publication

An Official Publication of IGM Publication

Original Research Article

\title{
A Retrospective Laboratory Study of the Spectrum of Haemoglobin Disorders in North Goa District Hospital
}

\author{
Authors \\ Dr Varsha Shailendra Munj*, Dr Melanie Dias, Dr Nelishka Gomes \\ Department of Pathology, North District Hospital, Peddem Mapusa - Goa \\ *Corresponding Author \\ Dr Varsha Shailendra Munj \\ Department of Pathology, North district Hospital, Peddem Mapusa - Goa Pin Code 403507
}

\begin{abstract}
Introduction: Haemoglobinopathies are abnormal hemoglobin related disorders which constitute major bulk of non communicable genetic disease worldwide and in India.

Aim of the Study: To detect clinically significant hemoglobinopathy by analyzing hematological profile and CE- HPLC (High Performance Liquid Chromatography) with associated limitations - a lab perspective.

Materials and Methods: This study was carried out in the Department of Pathology, North District Hospital over a period of 2 years.(January 2017 to 2019). HbA, HbA2, HbF and other variants of hemoglobin were studied by HPLC

Results: 1084 patients were tested, 130 cases were detected having abnormal hemoglobin pattern on chromatogram. $\beta$ Thalassemia trait constituted 89 cases followed by HbE trait (10 cases), HbS (7 cases), $\beta$ Thalassemia major (4 cases) compound HbE with $\beta$ Thalassemia (4 cases), HbS disease ( 3 cases), HbD (3) , $\delta \beta$ Thalassemia (3 cases), HPFH (2 cases),Compound HbE with $\delta \beta$ Thalassemia (1 case), HbE disease (3 cases) and Compound $\mathrm{HbS}$ with $\beta$ thalassemia (1 case). Additionally 18 cases (3 with abnormal initial peaks, 1 with high P3 and 14 cases with Borderline HbA2) were noted and 3 cases of borderline HbA2 were noted having macrocytic anemia

Conclusion: The present study provides a comprehensive data of the spectrum of hemoglobinopathies identified at North district hospital Goa reflecting the magnitude of the problem which may be just the tip of the iceberg. Hence, preventive and control measures need to be taken by the policy makers and the health care department of the state.
\end{abstract}

\section{Introduction}

Nutritional Anemia's are the commonest type of Anemia affecting the population of India $^{4}$. Haemoglobinopathies are the hidden problem amongst these anemias. Haemoglobinopathies are abnormal hemoglobin related disorders which constitute major bulk of non communicable genetic disease worldwide and in India $^{1}$. Thalassemia and abnormal variant hemoglobins like $\mathrm{HbS}, \mathrm{HbE}, \mathrm{HbD}$, etc are the plethora of Hemoglobin variants prevalent in India ${ }^{1,2}$. Being recessively inherited, these disorders may manifest in children of healthy carrier couple. Hence there needs to be awareness that over the 
next decade it may be responsible for major hemoglobinopathies requiring lifelong blood transfusion and iron chelation therapy with monitoring ${ }^{1,3,4}$. The only cure available is bone marrow transplant which is possible in just few patients who have got a HLA matched donor ${ }^{1}$. The cost of supportive care and management of bone marrow transplant is estimated to be very high causing enormous financial burden on the state $^{2}$.

\section{Aim of the Study}

1. To detect clinically significant Haemoglobinopathies not responding to iron therapy by analyzing hematological profile and CE- HPLC (High Performance Liquid Chromatography)

2. Correlating Haemoglobinopathies with ethnicity and impact of migration on epidemiology in Goa

3. Limitations and problems associated in diagnosis in lab's having limited resources - a laboratory Perspective

\section{Materials and Methods}

This study was carried out in the Department of Pathology, North District Hospital over a period of 2 years.(January 2017 to 2019)The samples included were of Patients who were anemic not responding to conventional therapy, Clinically suspected cases of Haemoglobinopathies, Antenatal patients and Family members of patients with Haemoglobinopathies. Total number of cases included in the study was $1084.2 \mathrm{ml}$ blood was collected in EDTA bulb and red cell indices were analysed on automated cell counter (Mindray 3600). $\mathrm{HbA}, \mathrm{HbA} 2, \mathrm{HbF}$ and other variants of hemoglobin were studied by HPLC variant hemoglobin testing system (Bio- rad Laboratories Inc CA USA). Reticulocyte and peripheral smear examination was done. Chromatograms were interpreted taking into consideration red cell indices, retic count and ethnic origin of the patient. The chromatograms were reported by referring to D-10 hemoglobin testing system library of chromatograms.

\section{Results}

1084 patients were tested, 130 cases were detected having abnormal hemoglobin pattern on chromatogram. Additionally 18 cases (3 with abnormal initial peaks, 1 with high P3 and 14 cases with Borderline $\mathrm{HbA} 2$ ) were noted, 3 cases of borderline $\mathrm{HbA} 2$ were noted having macrocytic anemia. Mean values of red cell parameter and hemoglobin fraction (HPLC) table was prepared (refer table 1)

Table 1: Mean values of red cell parameter and hemoglobin fraction (HPLC) table was prepared

\begin{tabular}{|c|c|c|c|c|c|c|c|c|c|c|}
\hline Hb variant & Hemoglobin & RBC count & MCV & МCH & MCHC & $\mathbf{H b A}$ & HbA2 & HbF & Others & $\begin{array}{l}\text { Number } \\
\text { of cases }\end{array}$ \\
\hline$\beta$ Thalassemia trait & $9.02^{+}, 2.3$ & $4.6+/-1.5$ & $68+/-10$ & $2-+/-4$ & $29+/-3$ & $89+/-2.5$ & $4.0+4.8$ & $1+/-0.5$ & - & 89 \\
\hline$\beta$ Thalassemia major & $3.5+/-1.5$ & $2.5+/-1.5$ & $72.2+/-5.2$ & $20+/-2$ & $28+/-2$ & $23+/-22$ & $4+/-1.5$ & $64+/-28$ & - & 4 \\
\hline HbE trait & $10.3+/-2.5$ & $4.2+/-1.5$ & $81+/-1.5$ & $25+/-3$ & $31.5+/-2.5$ & $61+/-6.5$ & $27+/-4.5$ & $1.5+/-1.02$ & - & 10 \\
\hline HbE disease & $11.2+/-1.5$ & $5.9+/-0.9$ & $60+/-4.5$ & $20+/-1.5$ & $32+/-2.1$ & $3.8+/-1.5$ & $80+/-2.8$ & $4+/-0.2$ & & 3 \\
\hline $\begin{array}{l}\text { Compound Hb E with } \\
\beta \text { Thalassemia }\end{array}$ & $8.5+/-1.9$ & $5.16+/-1.5$ & $62+/-2.2$ & $20+/-1.5$ & $30.3+/-2.5$ & $17.5+/-9.5$ & $62+/-8$ & $9.5+/-4.5$ & - & 4 \\
\hline HbS trait & $9.6+/-3.5$ & $3.8+/-1.4$ & $75+/-13$ & $23.2+/-5$ & $30+/-2.5$ & $40.4+/-8.4$ & $3.2+/-0.5$ & $2.5+/-1.8$ & $\begin{array}{c}\mathrm{HbS} 28.5 \\
+/-10.2\end{array}$ & 7 \\
\hline Hb S disease & $5.2+/-3$ & $2.5+/-1.5$ & $66+/-8$ & $26+/-4$ & $27+/-2.5$ & $20.5+/-15.5$ & $2.5+/-1.5$ & $12.5+/-11$ & $\begin{array}{c}\text { HbS 78+/- } \\
11\end{array}$ & 3 \\
\hline HbD & 11.6 & 4.2 & 81.2 & 26.8 & 33.1 & 54.2 & 2.18 & 1.6 & $\mathrm{HbD} 40.2$ & 3 \\
\hline HРFH & $12+/-1$ & $3.5+/-2.8$ & $83+/-3.4$ & $30.8+/-1.2$ & $35.4+/-2.5$ & $65+/-11.2$ & $3.5+/-1.2$ & $17+/-10$ & - & 2 \\
\hline$\delta \beta$ thalassemia & $9.1+/-2$ & $4.3+/-1.2$ & $66+/-10$ & $21+/-4$ & $28+/-2.9$ & $50.9+/-2.2$ & $3.3+/-0.6$ & $1+/-0.5$ & - & 3 \\
\hline $\begin{array}{l}\text { Compound HbE with } \\
\delta \beta \text { Thalassemia }\end{array}$ & 7.5 & 3.2 & 68.2 & 17.1 & 28 & 2.5 & 30.2 & 16.4 & - & 1 \\
\hline $\begin{array}{l}\text { Compound HbS with } \\
\beta \text { thalassemia }\end{array}$ & 7.2 & 3.8 & 72.5 & 23.4 & 30.2 & 24.6 & 7.4 & 13.7 & $\mathrm{HbS} 54.3$ & 1 \\
\hline
\end{tabular}




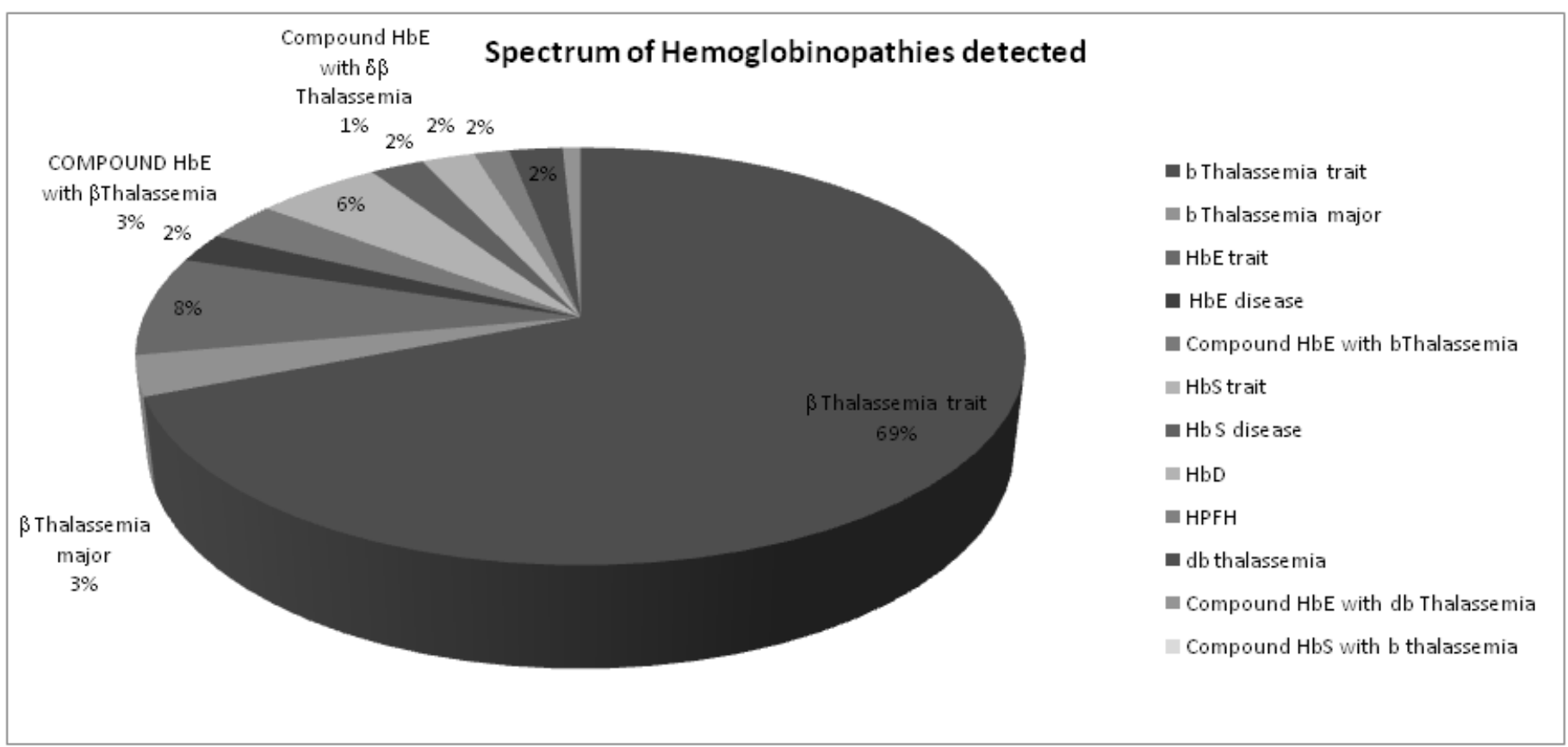

Table 2: Age wise distribution of hemoglobinopathies

\begin{tabular}{|l|c|}
\hline Age distribution & Number of cases \\
\hline$<10$ years & 64 \\
\hline $10-45$ & 52 \\
\hline$>45$ & 14 \\
\hline
\end{tabular}

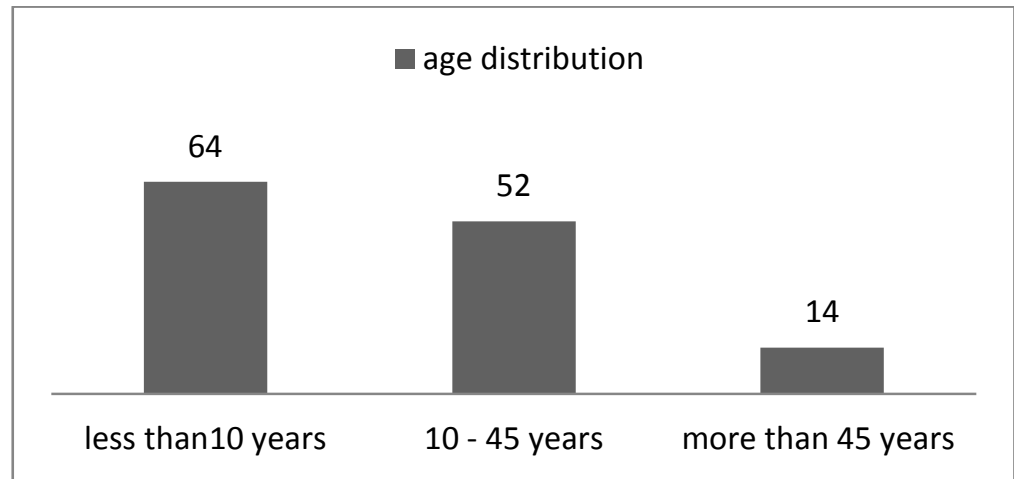

Table 3: Gender wise distribution of Hemoglobinopathies

\begin{tabular}{|l|c|}
\hline Gender & Number of cases \\
\hline Male & 53 \\
\hline female & 77 \\
\hline
\end{tabular}

\begin{tabular}{|c|c|}
\hline \multirow{2}{*}{\multicolumn{2}{|c|}{$\begin{array}{c}\text { Gender wise distribution of } \\
\text { hemoglobinopathies } \\
\text { number of cases }\end{array}$}} \\
\hline & \\
\hline 53 & 77 \\
\hline male & emale \\
\hline
\end{tabular}


Table 4: Religion wise (community wise) distribution of hemoglobinopathies

\begin{tabular}{|l|c|}
\hline Religion & Number of cases \\
\hline Muslim & 68 \\
\hline Hindus & 47 \\
\hline Christians & 6 \\
\hline Tribal & 9 \\
\hline
\end{tabular}

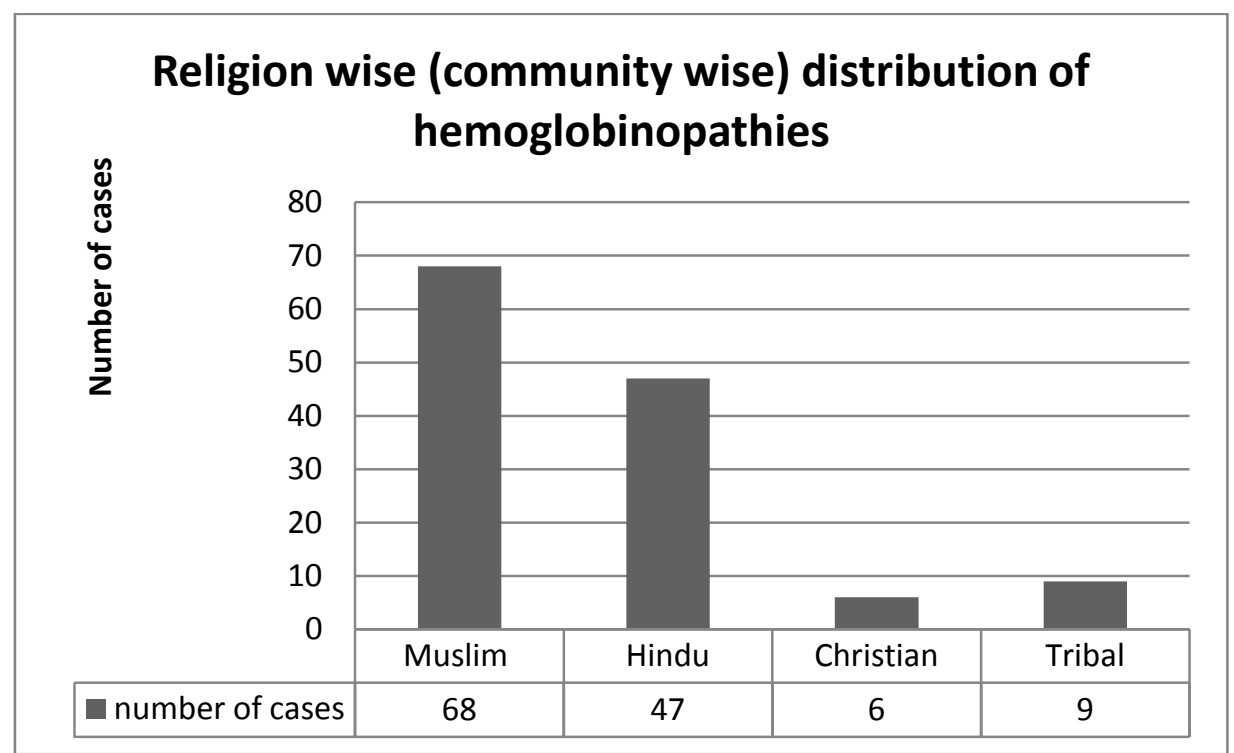

\section{Observation}

Commonest hemoglobinopathies found in our study was $\beta$ Thalassemia trait followed by $\mathrm{HbE}$ and $\mathrm{HbS}$. Hemoglobinopathies were common in Children and women in the reproductive age group. Muslim community had maximum number of hemoglobinopathy related disorders followed by Hindus and tribals. Sickle cell trait and disease was seen in tribal population migrated to Goa from Maharashtra and Jharkand. Compound hemoglobinopathies are found in Goa. Borderline $\mathrm{HbA} 2$, peaks in first minute of elution, abnormal P3 waves are problems in routine diagnosis hemoglobinopathies and need DNA analysis for confirmation of hemoglobinopathies.

\section{Discussion}

Inherited disorders of hemoglobinopathies are the most common monogenic disease in India ${ }^{4}$. Thalassemia is the most prevalent hemoglobinopathy with a carrier frequency of 3 to $4 \%$ in India ${ }^{5}$. It is observed in certain communities like Muslims, Sindhis, Punjabis, Bengalis and Gujaratis having higher carrier state (3 to $17 \%)^{6}$.
$\mathrm{HbS}$ is prevalent in tribal population of southern, central and western states. $\mathrm{HbE}$ is common in North eastern states of India. HbD is seen in Punjab. The cumulative gene frequency for sickle cell, $\mathrm{HbE}$ and $\mathrm{HbD}$ is $5.35 \%$ in India. Due to migration of ethnically diverse group of patients, there is mixing of people causing increase in hemoglobinopathies and it will be responsible major clinically significant hemoglobinopathies in the coming decades ${ }^{1}$.Our study carried out in North district Hospital laboratory shows a spectrum of different Haemoglobinopathies which reflects the presence of different hemoglobin variants due to ethnic groups who have migrated to Goa and settled in Goa. The heterozygous states are of little clinical significance but when combined with other variants may give rise to severe diseases. Consanguineous marriages, cross marriages among the affected patients and mixing of people from different regions may be responsible for increase in severe form of Haemoglobinopathies in coming decades. The aim of the study was to detect various Haemoglobinopathies by HPLC which has 
advantage of quantifying $\mathrm{HbF}, \mathrm{HbA} 2$ along with detection of variants in a single test. HPLC is less labor intensive, has rapid turnaround time, is sensitive, specific and a reproducible test, ideal for clinical laboratory which can replace alkaline and acid electrophoresis which cannot detect all abnormal variants of hemoglobin ${ }^{5,7,8}$. Quantification of HbA2 and HbF levels by HPLC along with $\mathrm{CBC}$ was of importance in this study which helped to arrive at a conclusive diagnosis as genetic studies facilities are not available ${ }^{10,11}$. However only carrier states with clear cut diagnostic values are detectable on HPLC. Cases whose values fall in equivocal or borderline range or those having initial abnormal peaks may be missed, these may be a hint to perform genetic counselling with DNA analysis. As confirmatory diagnostic facilities are not easily available. Parental screening with iron studies and HPLC may be done before referring the patient for genetic testing ${ }^{7,9}$. Antenatal patients having borderline or suspicious results, whose partner has one or the other hemoglobinopathy or is also having borderline results, should be referred for genetic counselling and testing ${ }^{1}$. Concomitant beta Thalassemia trait and iron deficiency, which is more common in children and pregnant women, are difficult to diagnose conclusively on $\mathrm{HPLC}^{10}$. Refractory microcytic hypochromic anemia with borderline or reduced $\mathrm{HbA} 2$ on HPLC may be investigated for alpha Thalassemia, which is the commonest hemoglobinopathy in India. It is diagnosed by molecular genotyping, thus preventing unnecessary iron therapy ${ }^{9}$. Iron deficiency tends to reduce $\mathrm{HbA} 2$ according to some studies ${ }^{12}$. Hence simultaneous iron studies along with HPLC can be used for screening of cases with borderline results. It may be an alarm to perform genetic testing. Also there needs awareness that megaloblastic anemia causes falsely elevated $\mathrm{HbA} 2$ values. We got 3 such cases in our study with elevated $\mathrm{HbA} 2$ and macrocytosis $^{13}$. HPFH and Delta-beta Thalassemia have similar HPLC results and should be differentiated based on red cell indices. However confirmation is done by DNA analysis ${ }^{7}$.

\section{Conclusion}

The present study provides a comprehensive data of the spectrum of hemoglobinopathies identified at North district hospital Goa reflecting the magnitude of the problem which may be just the tip of the iceberg. Hence, preventive and control measures need to be taken by the policy makers and the health care department of the state. The commonest population affected were children and women in reproductive age group, hence these groups may be the targets for carrier screening through school health check up programs and antenatal testing . Also, increased awareness needs to be brought in both the general population and the healthcare givers about the existence of hemoglobinopathies. RBC indices, HPLC, screening of family members and ethnicity data can help to detect common abnormal Hemoglobinopathies. There has to be awareness about limitations and problems with routine diagnosis in the laboratory among the clinicians. Facility help for genetic testing for silent carriers and other abnormal peaks may be taken from reference labs or reference lab may be set up in the state.

\section{Acknowledgements}

Dr Geeta Kakodkar - Deputy Director, directorate of health services Goa

\section{References}

1. Prevention and control of hemoglobinopathies in India thalassemias, sickle cell disease and other variant hemoglobins National Health Mission (NHM), Ministry of Health \& Family Welfare, Government of India, (2016)

2. Past, present \& future scenario of thalassaemic care \& control in India Ishwar C. Verma, Renu Saxena \& Sudha 
Kohli. Indian J Med Res 134, October 2011, pp 507-521

3. The burden of haemoglobinopathies in India and the challenges ahead R. S. Balgir. Current science, vol. 79, no. 11, 10 December 2000

4. The Burden of Haemoglobinopathies in India - Time to Wake Up? MB Agarwal. JAPI VOL. 53 December 2005, pg 1017 to 1018

5. Spectrum of haemoglobinopathies diagnosed by cation exchange-HPLC \& modulating effects of nutritional deficiency anaemias from north India. Seema Rao, Rakhee Kar, Sanjeev Kumar Gupta. Indian J Med Res. 2010 Nov; 132(5): 513-519.

6. Prevalence of $\beta$-thalassemia and other haemoglobinopathies in six cities in India: a multicentre study D. Mohanty, R. B. Colah, A. C. Gorakshakar et al . J Community Genet. 2013 Jan; 4(1): 33-42

7. Bio- Rad laboratories haemoglobin testing d10 testing system. Library of chromatograms.

8. Bio- Rad VARIANT ${ }^{\mathrm{TM}}$ II $\beta$-thalassemia Short Program

9. $\beta$-Thalassemia mutations in subjects with borderline $\mathrm{HbA}_{2}$ values: a pilot study in North India. Rangan A, Sharma P, Dadu Tet al. Clin Chem Lab Med. 2011 Sep 6; 49(12):2069-72. doi: 10.1515/CCLM.2011.696

10. Spectrum of Haemoglobinopathies in Anaemic Patients Admitted in Tertiary Care Hospital in Jharkhand". Dr. Sujeet Marandi MD, Dr. Rishi Tuhin Guria MD, Dr. Poonam Kumari MS. IOSR Journal of Dental and Medical Sciences (IOSRJDMS). 2279-0861.Volume 16, Issue 8 Ver. III (Aug. 2017), PP 71-73
11. Detection of Hemaglobinopathies in Anemic Children by HPLC method - A Hospital Based Study Dr. Mukesh Kumar Niraj ,Dr. Pradeep Prasad IOSR Journal of Dental and Medical Sciences. ((IOSR _ JDMS) e - ISSN .2279-0853, p-ISSN: 2279-0861.Volume 16, Issue 6 Ver. VIII (June. 2017), PP 73-77.

12. Galanello R, Elefthereiou A, Traeger Synodinos J , Old, J Petrou, , Angastiniotis $M$. Prevention of Thalassaemias and Other Haemoglobin Disorders. Thalassemia international Federation 2003, Vol.1

13. Giordano P.C Carrier diagnostics and Prevention of Hemoglobinopathies using high performance liquid Chromatography , Bio - Rad laboratories 2006. 